\title{
Prey preferences of the chimpanzee (Pan troglodytes)
}

\author{
Cassandra Bugir ${ }^{1}$, Thomas Butynski², and Matthew Hayward ${ }^{1}$ \\ ${ }^{1}$ The University of Newcastle \\ ${ }^{2}$ Lolldaiga Hills Research Programme
}

February 18, 2021

\begin{abstract}
Chimpanzees Pan troglodytes are the closest extant relative of modern humans, and are often used as a model organism to help understand prehistoric human behavior and ecology. Originally presumed herbivorous, chimpanzees have been observed hunting 24 species of birds, ungulates, rodents, monkeys, and other primates, using an array of techniques from tools to group cooperation. Using the literature on chimpanzee hunting behavior and diet from 13 studies, we aimed to determine the prey preferences of chimpanzees. We extracted data on prey-specific variables such as targeted species, their body weight, and their abundance within the prey community, and hunter-specific variables such as hunting method, and chimpanzee group size and sex ratio. We used these in a generalized linear model to determine what factors drive chimpanzee prey preference. We calculated a Jacobs' Index value for each prey species killed at two sites in Uganda and two sites in Tanzania. Chimpanzees prefer prey with a body weight of $7.6 \pm 0.4 \mathrm{~kg}$ or less, which corresponds to animals such as juvenile bushbuck Tragelaphus scriptus and guereza colobus monkeys Colobus guereza. Sex ratio in chimpanzee groups appears to drive chimpanzee prey preference, where chimpanzees increasingly prefer prey when in male-dominated groups. Prey preference information from chimpanzee research can assist conservation management programs by identifying key prey species to manage, as well as contribute to a better understanding of the evolution of human hunting behavior.
\end{abstract}

\section{Hosted file}

2021_CKB_Chimp.pdf available at https://authorea.com/users/396498/articles/509652-preypreferences-of-the-chimpanzee-pan-troglodytes 